\title{
UTILISATION OF RMC WASTE WITH CHEMICAL ADMIXTURES TO MANUFACTURING OF SUSTAINABLE BUILDING COMPONENTS
}

\author{
L. Krishnaraj ${ }^{1, *}$, R. Suba Lakshmi ${ }^{2}$ and P.T. Ravichandran ${ }^{3}$ \\ ${ }^{1}$ Department of Civil Engineering, SRM University, Kattankulathur-603203, Tamil Nadu, India \\ ${ }^{2}$ Department of Civil Engineering, Sri Sai Ram Engineering College, \\ Tambaram-600 044, Tamil Nadu, India \\ ${ }^{3}$ Department of Civil Engineering, SRM University, Kattankulathur-603203, Tamil Nadu, India \\ Address for Postal Correspondance: Department of Civil Engineering, SRM University, \\ Kattankulathur, Kancheepuram-603203, Tamil Nadu, India \\ *E-mail : krishnarajcivil@gmail.com
}

\begin{abstract}
This study made an attempt to reduce the usage of cement in the construction sector. While production of cement, the $\mathrm{CO}_{2}$ emission is unavoidable and polluting the environment also. To avoid the problems, the reuse of ready mix concrete waste generated from Ready Mix Concrete (RMC) plant is best practices. In this work, the impact of Recycled Coarse Aggregates (RCA), Recycled Concrete Dust (RCD) on compressive strength of building parts were studied. The compressive strength parameter was performed on the preparation of Paver, Solid and Hollow blocks with various mix proportions using cement replaced by 25 and $50 \%$ of RCD and Fly ash. The control specimens we prepared by utilizing cement only. Mainly, all the cement blend mix were made with and without added additives. From the compressive strength test results, RCD 50\% with additives blended mix has compared with OPC control sample in paver, solid and hollow blocks give 5, 14 and 25\% increase in strength at the age of 28 days testing. Reduction in cost due to OPC replaced by waste materials is another advantage of using RMC waste, were OPC replaced by RCD50\% with admixtures is selected as an economical trail mix in paver block, Solid block and Hollow block. The utilization of blocks using RMC waste decreases the cost of preparing building parts, and environmental hazards compare to use of conventional materials.

Keywords: Recycled Cement Dust, Structural Building Components, Sustainable Materials, Paver Blocks, Solid Blocks, Compressive Strength.
\end{abstract}

(C) RASĀYAN. All rights reserved

\section{INTRODUCTION}

In India, the waste generation from construction industry is estimated around 14 million tons per annum, out of overall quantity which is 4 to 6 million tons per annum are RMC plant waste. This waste is either dumped in RMC plant, or it is diverted towards landfill ${ }^{1,2}$. Also, production of a large amount of waste wash water coming from RMC plant leads to problems of Environmental impacts. National laws prohibit the disposal of such type of water, due to their extremely high $\mathrm{pH}$ value and suspended matter amount ${ }^{2}$. To clean the each transit mixer and sludge from the blades were cleaned by using approximately 120-200 liters of water. In addition to that, the plant and yard washed by using around 1000 - 1500 liters of water used at the end of each completion day ${ }^{3,4}$. This wash water gets harden and becomes very tiny cement dust particle due to the truck movement over it. This creates an unhealthy environment and harmfulness to breathe ${ }^{5}$.

The reuse of these RCA and RCD materials in the manufacturing of Paver, Solid and Hollow blocks gives an agreeable result to a portion of the ecological tensions and difficulties connected with a waste administration in RMC plant. In this investigational work, the effects cement replaced by FA (25\% and $50 \%) \&$ Recycled cement dust RCD (25\% and $50 \%)$ and course aggregate by Recycled course aggregate 
(RCA 100\%) on mechanical strength and durability characteristics of hardened concrete Paver block, Solid block, Hollow block with and without addition of admixtures are studied.

\section{Material Processing Technique}

Recycled cement dust and Recycled concrete aggregate collected from RMC Plant. This gathered material is pulverized by sledge to isolate the aggregates, and tidy particles and concrete tidy is sieved and conveyed to the fineness of bond. These are reduced to their sizes in a smaller fraction, sieved to aggregate size and for cement fineness. On these isolated aggregates different testicles are led in research centre according to IS and IRC code and their outcomes are contrasted and normal aggregates. Obstructs with RCD, FA and a section trade for concrete considering it as a Pozzolanic material is additionally done ${ }^{5,6-9}$. Paver, Solid, Hollow pieces with measurements relating to Indian Standard codes are thrown utilizing Cement, Fine aggregates, Finer coarse aggregates, Fly fiery remains, Recycled Coarse Aggregate.

\section{Materials Used}

\section{EXPERIMENTAL}

The materials utilized as a part of this venture are Cement, Fine aggregates, Coarse aggregates, Fly ash, Coarse Aggregate, Recycled Coarse aggregates and Admixtures. In lab tests were directed according to IRC SP63 $3^{10}$ and IS 10262 codal arrangements of the materials to adopt their properties. Different tests on materials were directed to concentrate on the possessions of materials utilized, to cast Paver, Solid and hollow blocks using RCD and RCA. The blocks cast with different trail blends based upon the blend outline touched base, to acquire the required quality. The specific gravity and strength test significances of different materials are given underneath.

\section{Mix Design and Material Proportions}

The blend outline of M30 review was done according to $10262-200912^{11}$ and was altered according to the rules of IRC: SP: 63-2004 for Paver blocks and IS 15658\& IS $2185^{12}$ for Solid and Hollow blocks to accomplish the characteristic strength of $30 \mathrm{MPa}$

The trail I is a traditional blend. Trial II was cast by fulfilling the necessities given in the codes, with slight adjustments in the proportion was. The adjusted proportion was the incomplete substitution of concrete by RCD and completely substitution of coarse aggregates by RCA. Trial III was cast by in partial substitution of the bond by FA and completely substitution of Coarse aggregates by RCA. Trail IV was the replacement of concrete by $25 \% \mathrm{RCD}, 25 \% \mathrm{FA}$ and completely substitution of coarse aggregates by RCA. For every one of the trials, V to VIII with admixtures are additionally landed because of supplanting with reusing the material to maintain quality.

\section{Design of Paver Block}

The layout of paver blocks was done by: SP: 63-2004. The paver blocks used ought to have a reference compressive strength of $30 \mathrm{~N} / \mathrm{mm}^{2}$ and satisfy the essentials given in IRC: SP: 63-2004. The purposes of enthusiasm of these essentials given in IRC: SP: 63-2004 for interlocking paver blocks used is showed up as a part of Table-1. By comparing the properties of paver blocks used as a part of this study with IRC essentials, it watched that it fulfilled each one of the necessities.

\section{Design of Solid Block \& Hollow Block}

The outline of Solid blocks and Hollow blocks did according to IS 10262 and the mix ratio given in Table-2. The Solid and Hollow blocks utilized should have a base compressive strength of $5 \mathrm{~N} / \mathrm{mm}^{2}$ and 3 $\mathrm{N} / \mathrm{mm}^{2}$ separately at 28 days according to IS 2185 .

\section{Mix Combinations}

Test specimens of Paver block, Solid block and Hollow blocks are made of concrete with cement, fine aggregate and coarse aggregate by weight are cast with additives of Fly ash and Recycled cement dust, $100 \%$ replaces a replacement for cement by $25 \%$ and $50 \%$ and coarse aggregate. Approximately 8 
combinations of mixes prepared by varying cement content with and without admixtures for each specimen. Trail I is the benchmark which contains naturally available material with $100 \%$ OPC. Trail II is prepared by $100 \%$ replacement of Coarse Aggregate (CA) by Recycled Coarse Aggregate (RCA) and $50 \%$ of Cement by Recycled Cement Dust (RCD). Trail III prepared by $100 \%$ replacement of CA by RCA and $50 \%$ of Cement by Fly ash. Trail IV is the combination of $100 \%$ replacement of CA by RCA and 25\% of Cement by Fly ash and 25\% of cement by RCD. These four combinations prepared without admixtures. With the same combination Trail V, VI, VII, VIII prepared with admixture called Sun Proof Hollow Mix which accelerates the strength of blocks though it replaced with RMC waste ${ }^{2,8}$.

Table-1: IRC: SP 63 - 2004 Requirements for interlocking paver blocks

\begin{tabular}{l|l|l}
\hline \multicolumn{1}{c|}{ Parameters } & \multicolumn{1}{c|}{ IRC: SP63-2004 Requirements } & \multicolumn{1}{c}{ Values } \\
\hline Quantity of cement & $380 \mathrm{Kg} / \mathrm{m}^{3}$ to $425 \mathrm{Kg} / \mathrm{m}^{3}$ & $400 \mathrm{Kg} / \mathrm{m}^{3}$ \\
\hline Cement: Aggregate ratio & $1: 3$ to $1: 6$ & $4: 1$ \\
\hline Water Binder Ratio & $0.34-0.38$ & 0.38 \\
\hline Compressive strength & $30 \mathrm{~N} / \mathrm{mm}^{2}$ & $35-40 \mathrm{~N} / \mathrm{mm}^{2}$ \\
\hline
\end{tabular}

Table-2: The Mix Ratio As Designed IS 10262

\begin{tabular}{l|l|l|l|l|l}
\hline Mix Details & $\begin{array}{l}\text { Water } \\
\mathrm{lit} / \mathrm{m}^{3}\end{array}$ & $\begin{array}{l}\text { Cement } \\
\mathrm{Kg} / \mathrm{m}^{3}\end{array}$ & $\begin{array}{l}\text { Fine aggregate } \\
\mathrm{Kg} / \mathrm{m}^{3}\end{array}$ & $\begin{array}{l}\text { Coarse aggregate } \\
\mathrm{Kg} / \mathrm{m}^{3}\end{array}$ & $\begin{array}{l}\text { Chemical admixtures } \\
\mathrm{lit} / \mathrm{m}^{3}\end{array}$ \\
\hline Mix Ratio & 0.5 & 1 & 4.58 & 5.39 & 0,014 \\
\hline Quantity & 191.6 & 203 & 930 & 1094 & 0.6 \\
\hline
\end{tabular}

\section{Preparation of Specimen}

Paver, Solid\& Hollow Blocks of size $200 \mathrm{~mm}$ X $150 \mathrm{~mm} \mathrm{X} 60 \mathrm{~mm}$ (Paver Block as per IRC SP 63) and $200 \mathrm{~mm}$ X $150 \mathrm{~mm}$ X $60 \mathrm{~mm}$ (Solid \& Hollow block as per IS 2185) were cast and tested for 7, 14 and 28 days of curing period.

Table-3: Fineness modulus of FA, RCD

\begin{tabular}{c|c|c|c|c|c|c|c|c|c}
\hline \multicolumn{2}{c|}{ Sieve Size (in mm) } & 4.75 & 2.36 & 1.18 & 0.6 & 0.425 & 0.15 & 0.075 & Pan \\
\hline \multirow{2}{*}{$\begin{array}{c}\text { of } \\
\text { Passing }\end{array}$} & Fly ash & 77.2 & 64.4 & 49.6 & 38.4 & 12.4 & 0.8 & 0 & 0 \\
\cline { 2 - 10 } & Cement dust & 76.6 & 68.2 & 61.8 & 55.4 & 53.6 & 50.2 & 49 & 0 \\
\hline
\end{tabular}

\section{Testing methods}

The compressive strength testing for paver, hollow and solid blocks cast were attempted and explored. Table 3 shows the compressive strength qualities for Paver, Solid and Hollow blocks for various trials conducted. From the compressive strength test results, the compressive strength estimations of various sorts and trails of blocks satisfy the essential except for Trail III and IV in paver blocks. In this way, the paver, hollow and solid blocks can be viewed as a suitable and fiscally useful substitution for OPC while casting.

\section{Physical properties}

\section{RESULTS AND DISCUSSION}

Materials utilized as a part of this study are Cement, Fine Aggregate, Finer Coarse Aggregate, Fly-ash, Coarse Aggregate, Recycled Coarse Aggregate, and Admixtures. Research facility tests directed according to IS codal arrangements on supplanting materials to decide particular gravity and fineness modulus. Particular gravity for fly cinder, RCD and RCA are 3.1, 1.1 and 7.8 separately. Fineness modulus of fly ash powder and RCD has appeared in Table-3.

\section{Normal Consistency (NC) and Setting Time}

Normal consistency test is done on OPC with the combination of RCD, RCA, \& FA. NC test was conducted for OPC (50\%) and replaced with RCD (50\%) gives 120mins of initial setting time and final setting time of $38 \mathrm{hrs}$. The OPC (50\%) and replaced with FA (50\%) gives 58 minutes of initial setting 
time and $20 \mathrm{hrs}$ of final setting time. OPC (50\%) and replaced with RCD (25\%) and FA (25\%) gives 70 minutes of initial setting time and $23 \mathrm{hrs}$ of final setting time ${ }^{13}$.

\section{Compressive Strength of Paver Block with and without Admixtures}

To think about the Compressive strength of Paver blocks with different extents, the OPC was supplanted by $50 \%$ of RCD and FA with and without added substances of admixtures were utilized to set up the paver blocks and tested at the age of 7, 14 and 28 days test comes about appeared in Figure-1.

From the test results, comparing OPC control specimen with RCD (50\%) with additives gives 5\% increase in compressive strength value. The without additives of $\operatorname{RCD}(50 \%), \mathrm{FA}(50 \%)$, with and without additives of $\mathrm{RCD}(25 \%)$ and $\mathrm{FA}(25 \%)$ mix proportions shows $12,56,28$ and $36 \%$ decrease in strength respectively at the age of 28 days, when compare to OPC control specimen but it attains 28 days strength as per IRC: SP: 63-2004. Also analysing the results of various proportions i.e. with admixtures of $\mathrm{RCD}(50 \%), \mathrm{FA}(50 \%)$ and $\mathrm{RCD}(25 \%)$ and $\mathrm{FA}(25 \%)$ replacement gives $15 \%, 20 \%$ and $12 \%$ increase in strength respectively, when compare to without additives of $\operatorname{RCD}(50 \%), \mathrm{FA}(50 \%)$ and $\operatorname{RCD}(25 \%)$ and $\mathrm{FA}(25 \%)$ mix proportions ${ }^{8}$.

\section{Compressive Strength of Solid Block with and without Admixtures}

To study the Compressive Strength of Solid blocks with different extents, the OPC was supplanted by $50 \%$ of RCD and FA with and without added substances of admixtures were utilized to set up the Solid blocks and directed test at the age of 7,14 and 28 days and test outcomes appeared in Figure-2.

From the test results, comparing OPC control specimen with RCD (50\%) and additives and RCD (25\%) + FA $(25 \%)+$ Additives gives $14 \%$ and $10 \%$ increase in compressive strength value. The without additives of $\mathrm{RCD}(50 \%), \mathrm{FA}(50 \%), \mathrm{RCD}(25 \%)+\mathrm{FA}(25 \%)$ and with additives if $\mathrm{FA}(50 \%)$ mix proportions shows 7 , 24,17 and $4 \%$ decrease in strength respectively at age of 28 days, when compare to OPC control specimen but it attains 28 days strength as per IS 2185 . Also analysing the results of various proportions i.e. with admixtures of $\mathrm{RCD}(50 \%), \mathrm{FA}(50 \%)$ and $\mathrm{RCD}(25 \%)+\mathrm{FA}(25 \%)$ replacement gives $22 \%, 27 \%$ and $31 \%$ increase in strength respectively, when compare to without additives of $\operatorname{RCD}(50 \%), \operatorname{FA}(50 \%)$ and $\mathrm{RCD}(25 \%)+\mathrm{FA}(25 \%)$ mix proportions ${ }^{14}$.

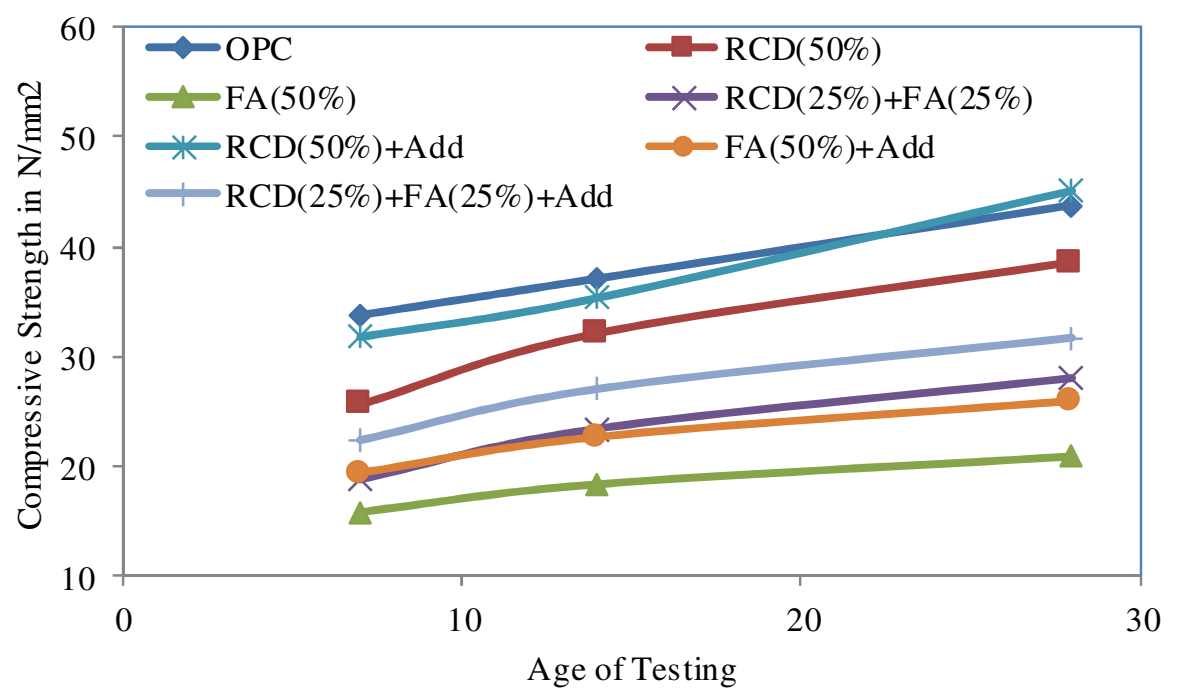

Fig.-1: Variation in compressive Strength of Paver block for various proportions

\section{Compressive Strength of Hollow Block with and without Admixtures}

To study the Compressive Strength of Hollow block with various proportions, the OPC replaced by 50\% of RCD and FA with and without additives of admixtures were used to prepare the Solid block and conducted the test at the age of 7,14 and 28 days and test results are shown in Figure-3. 
From the test results, comparing OPC control specimen with RCD (50\%) +Additives, FA (50\%) +Additives and RCD (25\%) +FA (25\%) +Additives gives 25\%, $3 \%$ and $22 \%$ increase in compressive strength. Whereas OPC with $\mathrm{RCD}(50 \%), \mathrm{FA}(50 \%)$ and $\mathrm{RCD}(25 \%)+\mathrm{FA}(25 \%)$ gives $3 \%, 29 \%$ and $17 \%$ decrease in strength respectively, when compare to OPC control specimen but it attains 28 days strength as per IS 2185. Also analysing the results of various proportions i.e. without and with admixtures, $\mathrm{RCD}(50 \%)+$ Additives, $\mathrm{FA}(50 \%)+$ Additives and $\mathrm{RCD}(25 \%)+\mathrm{FA}(25 \%)+$ Additives gives $28 \%$, $44 \%$ and $47 \%$ increase in strength respectively, when compare to $\mathrm{RCD}(50 \%), \mathrm{FA}(50 \%)$ and $\mathrm{RCD}(25 \%)+\mathrm{FA}(25 \%)$ without admixtures. Even though proportions without admixtures reaches the permissible value of Hollow block at 28 days, proportions additives with admixtures gives better strength ${ }^{15}$.

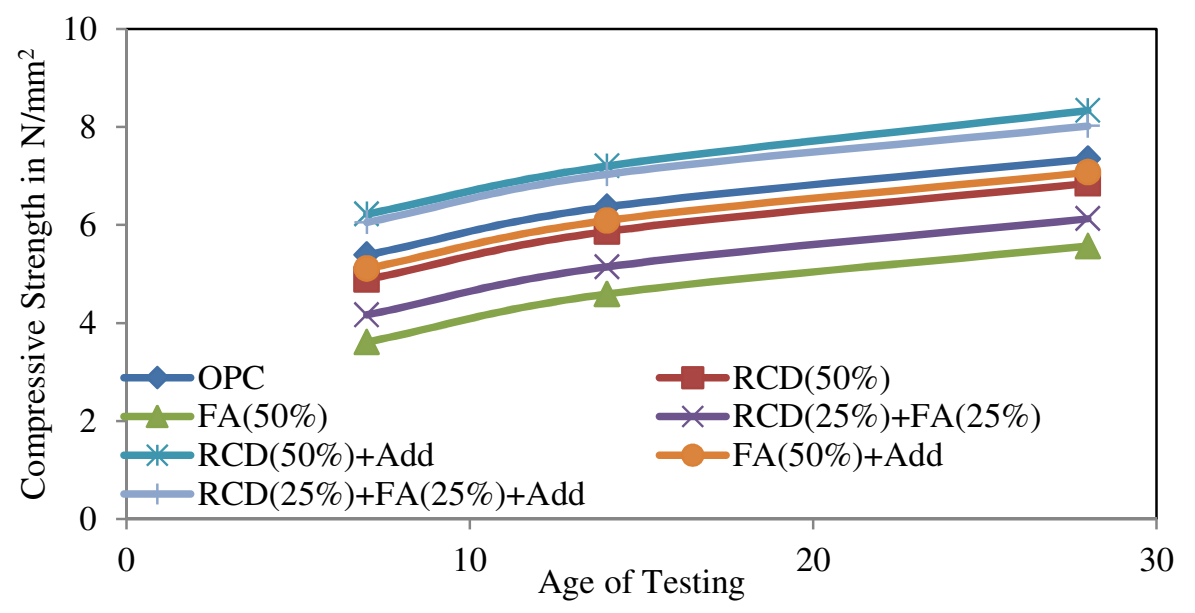

Fig.-2: Variation in compressive Strength of Solid block for various proportions

\section{Compressive Strength of Blocks}

The compressive strength of paver blocks, solid blocks and hollow blocks specimens at the age of 28 days testing results shows in Figure-4. From the test results its observed that, the effective replacement of OPC specimens in paver blocks is $\mathrm{RCD}(50 \%)$, in solid block is $\mathrm{RCD}(50 \%)$ and $\mathrm{RCD}(25 \%)+\mathrm{FA}(25 \%)$, in hollow blocks is with additives of RCD (50\%), FA (50\%) and RCD (25\%) +FA (25\%) respectively. In ultimate the $\operatorname{RCD}(50 \%)$ with additives is the best replacement in all types of block.

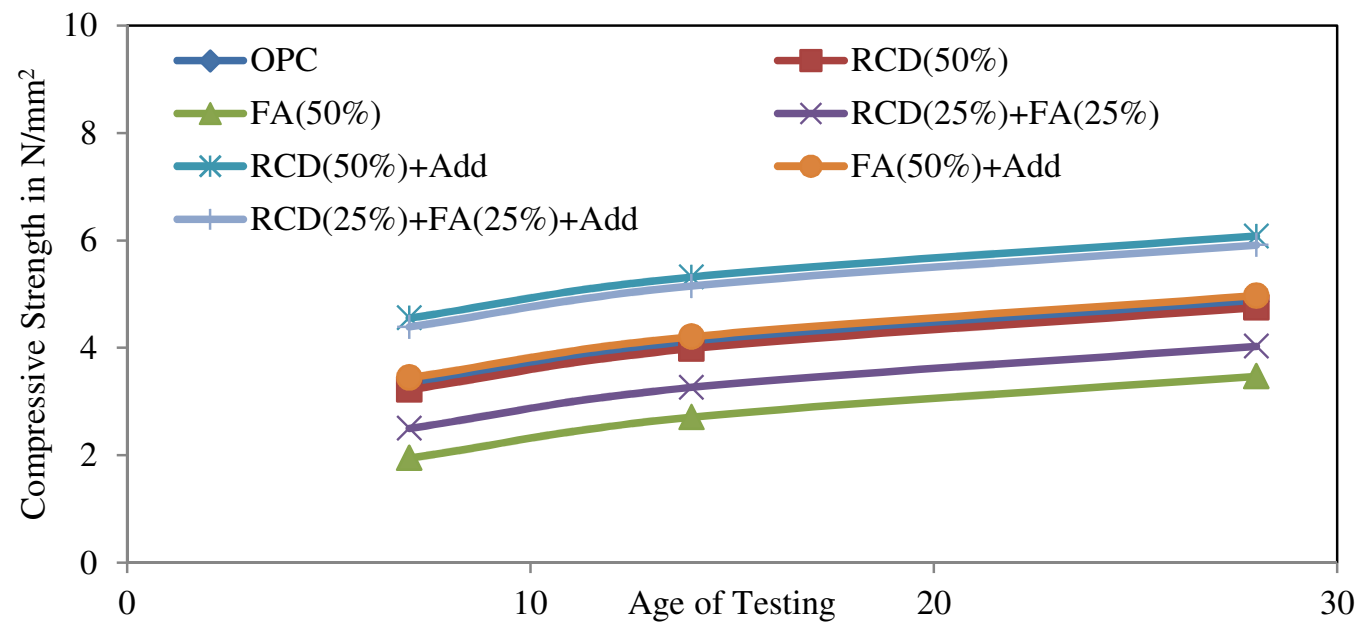

Fig.-3: Variation in compressive Strength of Hollow block for various proportions

\section{Mechanical Properties of Aggregate}

The laboratory experimental tests results steered as per IS codal requirements on coarse aggregate and recycled coarse aggregate to determine the variation in mechanical property and results are mentioned in Figure-5. From the results, its Shows the difference in mechanical property of coarse aggregate and 
recycled coarse aggregate. For use of pavements aggregate value should be 20-30\%. Even RCD is Impact value is less than CA it satisfies the permissible limits. Also, the value should not exceed $40 \%$ for CV and $\mathrm{AV}$. Though it is a recycled aggregate the $\mathrm{CV} \& \mathrm{AV}$ value is greater than CA but not exceeding the limits ${ }^{16}$.

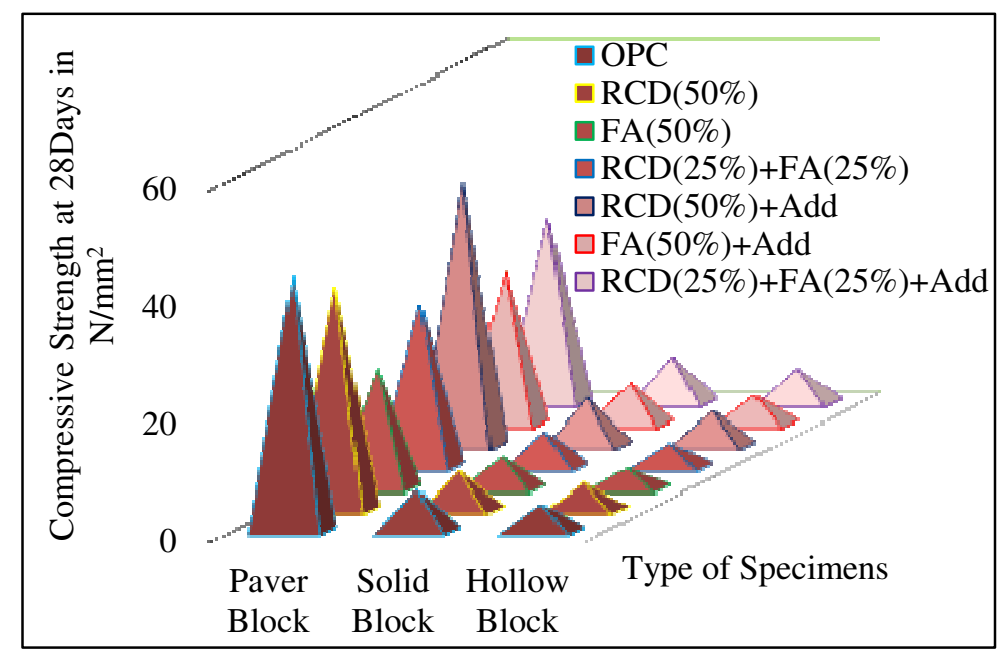

\section{Cost Analysis}

Fig.-4: Comparison of compressive strength of different block specimens

The manufacturing rates estimation of paver, solid and hollow blocks was analysed and shown in Figure6. From the results, in overall OPC sample replaced by $\mathrm{RCD}(50 \%), \mathrm{RCD}(25 \%)$ and $\mathrm{FA}(25 \%)$ mix proportions takes the minimum cost is spent on manufacturing the paver, solid and hollow blocks. The cost of manufacture of blocks by using the mixing of additives takes more cost compare to the without additives mixes, due to extra the additives $\operatorname{cost}^{17}$.

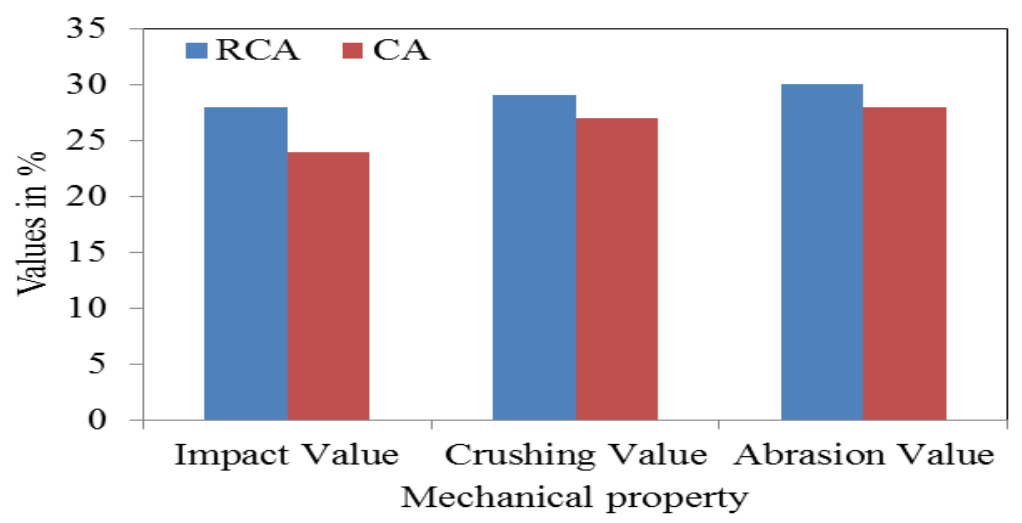

\section{Microstructural analysis of samples}

Fig.-5: Variation in mechanical property of CA \& RCA

The SEM images of OPC control specimen, $\mathrm{RCD}(50 \%), \mathrm{FA}(50 \%)$ and $\mathrm{RCD}(25 \%)+\mathrm{FA}(25 \%)$ samples were used to prepare the specimens and test at the age of 28 days of maximum strength results images were compared and shown in Figure-7a,b,c,d. From the SEM images it's clearly evident that the particle morphology and shape is good for RCD (50\%) and FA (50\%) samples compare to the OPC samples. ${ }^{18,19}$

\section{CONCLUSION}

In order to produce eco-friendly blocks from RMC wastes and fly ash, the mix designs prepared by replacing OPC by FA(25\% \& 50\%) \& Recycled cement dust $\mathrm{RCD}(25 \%$ \& $50 \%)$ and coarse aggregate by Recycled course aggregate (RCA 100\%) were casted on series of Paver, Solid and Hollow blocks. 
RASĀYAN J. Chem.

Vol. 10 | No. 2 |592 - 599 | April - June | 2017

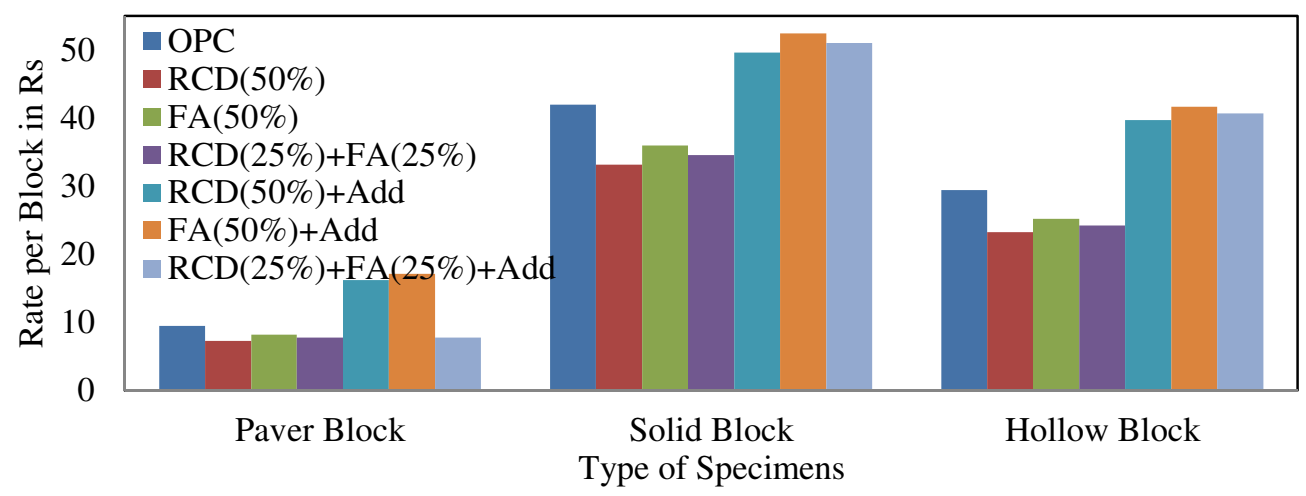

Fig.-6: Comparative rate analysis of paver block, solid block and hollow block

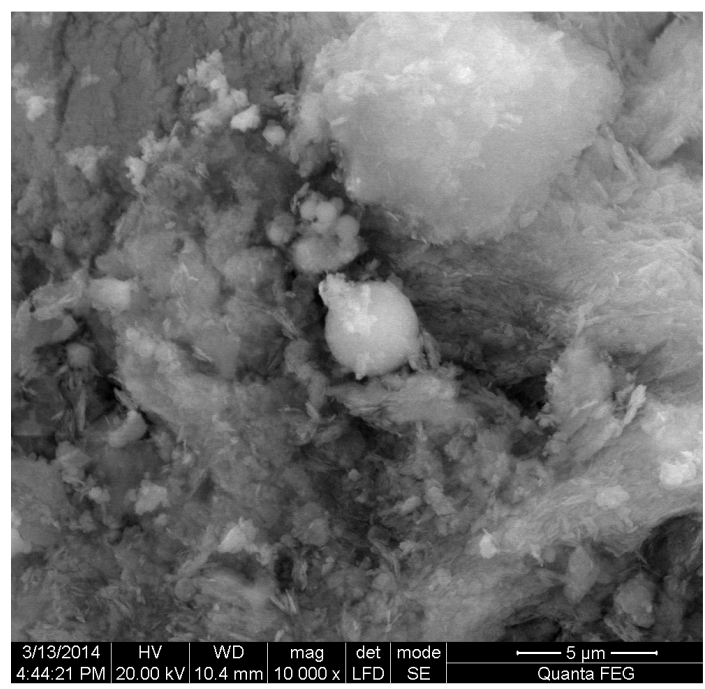

Fig.-7a: SEM images of OPC samples

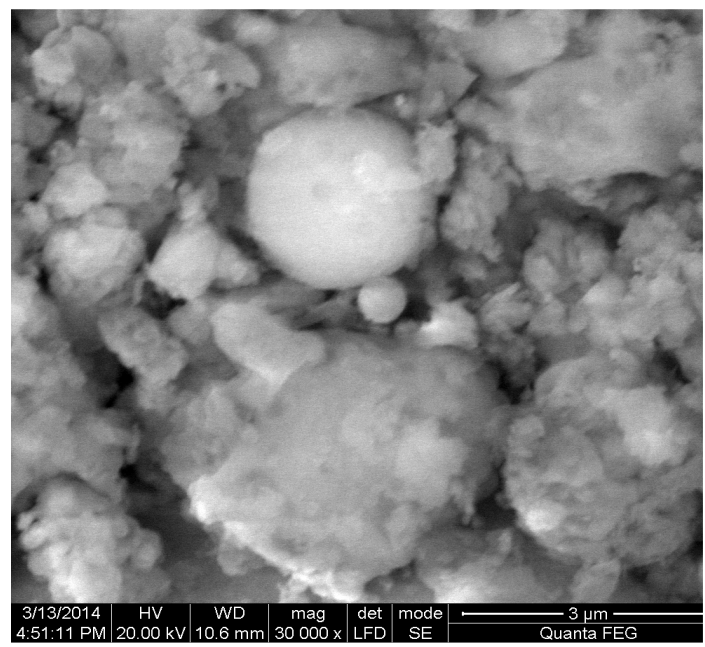

Fig.-7c: SEM images of FA(50\%) samples

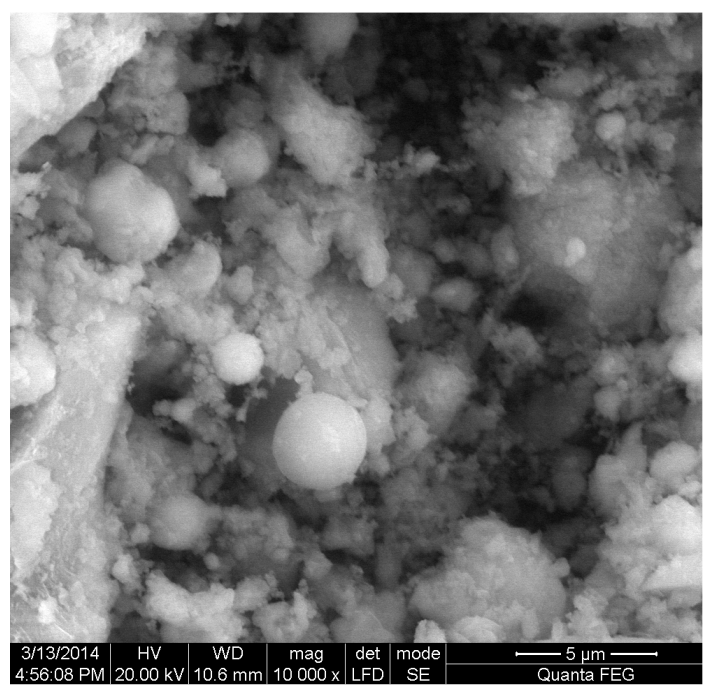

Fig.-7b: SEM images of RCD 50\% samples

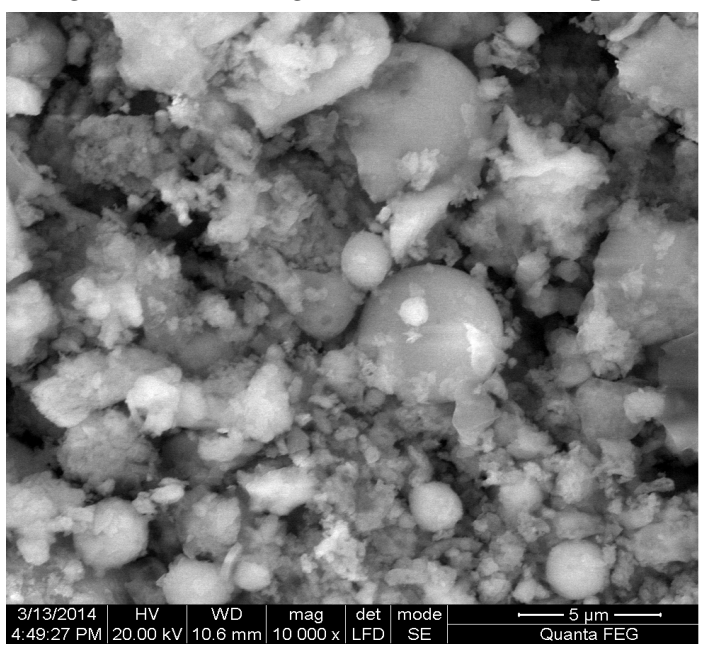

Fig.-7d: SEM images of RCD $(25 \%)+F A(25 \%)$ samples

The casted specimens then subjected to compressive strength tested at 7, $14 \& 28$ days respectively. From the test results, the following conclusion can be drawn:

- For Paver block, comparing OPC control specimen with RCD (50\%) and additives gives 5\% increase in compressive strength value at the age of 28 days testing as per IRC: SP 63-2004. For 
Solid block, comparing OPC control specimen with RCD (50\%) with additives and RCD (25\%) with FA (25\%) along with additives gives $14 \%$ and $10 \%$ increase in compressive strength value at the age of 28 days testing.

- For Hollow blocks, contrasting OPC control example and RCD (50\%) with Additives, FA (50\%) with Additives and RCD (25\%) and FA (25\%) with Additives gives higher compressive strength at 28 days testing.

- Reduction in cost is another advantage of using RMC waste were OPC with $\mathrm{RCD}(50 \%)$ is selected as an economical trail mix in paver block, Solid block and Hollow block without admixtures.

- RMC waste is viable utilized as a part of throwing of Paver, Solid and hollow blocks in this manner maintaining a strategic distance from land filling, contamination, and diminishment in the utilization of usually available assets. Additionally, the use of RMC waste prompts far lesser ecological dangers than traditional cement, likewise diminishes the contamination and a worldwide global warming.

\section{REFERENCES}

1. A. Bora, Journal of International Academic Research for Multidisciplinary, 2, 4(2014).

2. H. Chourasia, D. Jain, R. Joshi, M. T. Scholar, and A. Professor, International Journal for Scientific Research \& Development, 3, 7 (2015).

3. D. W. Gawatre, Indian Journal of Applied Research, 5(12), 243(2015).

4. M. Jain, International Journal of Scientific and Research Publications, 2, 1 (2012).

5. K. Kalingarani, H. D. P, J. R. M, and V. Sriramkumar, In Proceedings of National conference on advances in Traffic, Construction Materials and Environmental Engineering (ATCMEE), pp. 1217 (2011).

6. M. C. Nataraja and L. Das, In Proceedings of International Conference on Innovations in Civil Engineering, SCMS School of Engineering and Technology, pp. 1-5 (2014).

7. C. S. G. Penteado, E. Viviani De Carvalho, and R. C. C. Lintz, Journal of Cleaner Production, 112, 1 (2016).

8. P. R. K. Rajkumar, K. D. Krishnan, P. T. Ravichandran, and T. A. Harini, Indian Journal of Science and Technology, 9, 5 (2016).

9. C. R. dos Santos, J. R. do A. Filho, R. M. C. Tubino, and I. A. H. Schneider, Geomaterials, 3, 2 (2013).

10. IRC: SP 63-2004, Guidelines for the use of Interlocking Concrete Block Pavement, New Delhi: The Indian Roads Congress.

11. IS: 10262-2009, Recommended Guidelines for Concrete Mix Design, New Delhi: Bureau of Indian Standards.

12. IS 2185-1 (2005): Concrete masonry units, Part 1: Hollow and Solid Concrete Blocks, New Delhi: Bureau of Indian Standards.

13. R.S.Shetty, International Journal of Chemical, Environmental and Biological Sciences, 1,4 (2013).

14. J. Thomas and P. M. Wilson, American Journal of Engineering Research, 2, 6 (2013).

15. H. Akbar, Gopal Krishnan, S. D. Prajapati, Rakesh Saini, Rasayan J. Chem. 9, 1 (2016).

16. R. Goplakrishnan, Rasayan J. Chem. 9, 3 (2016).

17. S. Vanitha, V. Natarajan, and M. Praba, Indian Journal of Science and Technology, 8, 12 (2015).

18. D. Wattanasiriwech, A. Saiton, and S. Wattanasiriwech, Journal of Cleaner Production, 17, 18 (2009).

19. R. C. Yeole and M. B. Varma, International Journal of Emerging Technology and Advanced Engineering, 4, 10 (2014).

[RJC-1670/2017] 